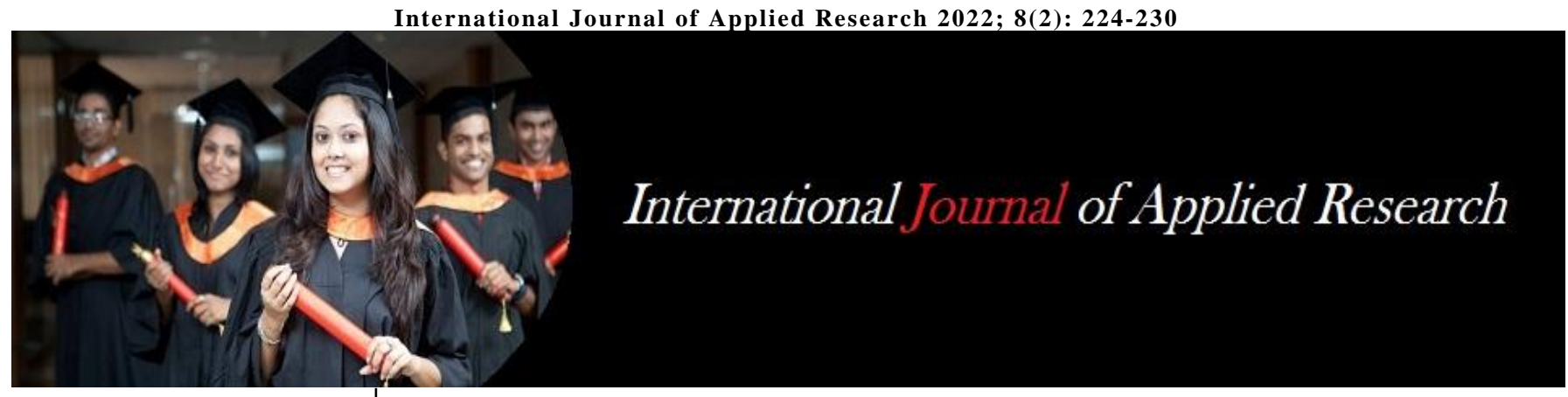

ISSN Print: 2394-7500 ISSN Online: 2394-5869 Impact Factor: 8.4 IJAR 2022; 8(2): 224-230 www.allresearchjournal.com Received: 16-11-2021 Accepted: 02-01-2022

Samuel Kofi Donkor PhD (Lead Author), Department of Physical Education and Sport Studies, School of Education and Leadership University of Ghana, Legon-Accra, Ghana

Fortune Selase Atsu Physical Education and Sports Unit Department of Science, E.P. College of Education, Amedzofe, Ghana

Julius Jerry Agortey Physical Education and Sports Unit Department of Science, St.Francis' College of Education, Hohoe, Ghana

Richmond Stephen Sorkpor Department of HPERS, Faculty of Science Education University of Education, Winneba, Ghana

Corresponding Author: Samuel Kofi Donkor PhD (Lead Author), Department of Physical Education and Sport Studies, School of Education and Leadership University of Ghana, Legon-Accra, Ghana

\section{Instructional practices in physical education setting: Teachers' utilization of instructional cues, supervision and frequency of pre-service teachers' participation in netball activities}

\author{
Samuel Kofi Donkor, Fortune Selase Atsu, Julius Jerry Agortey and \\ Richmond Stephen Sorkpor
}

DOI: https://doi.org/10.22271/allresearch.2022.v8.i2d.9440

\begin{abstract}
Instructional cues (IC) regularly occur in physical education (PE) practical lessons. However, not much research has been conducted into the effectiveness of these cues in teaching and learning environment. It is also noted that students generally exhibit low interest in netball activities, not only in the colleges of education but across all levels of education in Ghana. The study was based on pedagogical research in PE setting where we investigated teacher's utilization of instructional cues in teaching shooting skill in netball. We also investigated issues relating to supervision and the frequency of pre-service teachers' participation in netball activities. A total of 81 participants were randomly sampled for the study. They were composed of four PE teachers and 77 pre-service teachers from the first-year group of three selected Colleges of Education (CoE) in the Volta Region, Ghana. The study was descriptive in nature. A Senior University Lecturer with vast experience in research inspected self-developed data collection instrument and approved its capability of collecting data for the study. Frequency and percentage analyses of data were performed and presented in tables, graphs and charts. Major findings of the work revealed low level of supervision of pre-service teachers in netball activities. Participation level in netball activities and knowledge of basic netball skills were also found to be low among pre-service teachers. However, in the 60 minutes video-taped lesson, the rate per minute of constructive instructional cues (CIC) were higher than the rate per minute of destructive instructional cues (DIC), indicating that PE teachers were largely able to control destructions during utilization of instructional cues (IC) in teaching practical lessons involving netball shooting skill.
\end{abstract}

Keywords: Instructional cue (IC), Constructive instructional cues (CIC), Destructive instructional cues (DIC), Verbal IC, Non-verbal IC

\section{Introduction}

Literature has revealed an increasing popularity of netball activities and associated research applications in recent times (Bruce, 2018) ${ }^{[3]}$. Of particular interest to this pedagogical study is the teachers' utilization of instructional cues in teaching shooting skill in netball. Utilization of instructional cues (ICs) in teaching a motor skill to learners is very critical to the acquisition and perfection of the skill being taught. Instructional cues are words that quickly and efficiently communicate to the learner the proper way of performing a skill or a movement task. Mayer (2014) ${ }^{[14]}$ explains that cueing involves utilization of signals in a way that guides a learner's attention to important verbal or visual information in an instructional setting. Instructional cues are externally generated with a focus to improve body mechanics (Gokeler, et al., 2015) ${ }^{[10]}$. Highlighting the relevance of ICs, it is noted that "cues can be used to facilitate learning while also affording the flexibility that coaches may desire in their attempts to find the cues that work best for each athlete" (Becker \& Fairbrother, p.654). The explanation offered by Becker and Fairbrother does not mean that only sport coaches utilize IC to help athletes acquire correct movement techniques. Substantially, physical educators utilize ICs to help students execute skills efficiently in an instructional setting.

Generally, a cue consists of a word, phrase, or sentence that describes a particular aspect of a concept or skill. A teacher's overall instructional effectiveness depends heavily on how that teacher uses instructional cues. 
Learners need to be helped to grasp the correct procedures for executing a motor task such as shooting skill in netball. By so doing, coaches and for that matter physical educators require the use of instructional cues to help learners acquire critical skill points of the motor task.

Other interesting aspects of this study relate to supervision and pre-service teachers' participation in netball activities. It is worth noting that students generally exhibit low interest in netball activities, not only in the colleges of education but across all levels of education in Ghana. Supervision of every curricular activity should be seen as a key element to maximizing achievement of instructional goals of every educational institution. However, research on the effects of supervised training reveals that "there are mixed results of whether supervised or unsupervised exercise is more effective" (Curtis Fennel et al., p.27).

For the purpose of our study, we described the function of teachers' IC as constructive or destructive during skill teaching. In this regard, teacher's IC that we described as constructive should demonstrate key movement elements that were helpful and problem solving in executing the skill. Such constructive IC should also be tailored toward positive outcome of skill acquisition. In this regard, positive affirmative statements provided to students during skill teaching formed part of teachers' constructive IC. On the other hand, we described teacher's IC as destructive if the IC failed to achieve desirable outcome of skill execution. In this case, words that conveyed negative expression relating to the movement or skill being taught were part of the destructive function of teacher's IC. For instance, the teacher could say: "don't do that again", "not a good performance", "you have not performed a correct movement", etc. These negative expressions form part of destructive IC because they do not carry any specific information about the exact manner movement should be executed. It is to be noted that the ability to perform multitasks in instructional setting is a sign of an effective teacher. In particular, the ability to control destructions during skill teaching in every instructional setting is a pre-requisite that every teacher should aspire to achieve. Hence, we sought to investigate teachers' utilization of instructional cues, supervision and frequency of pre-service teachers' participation in netball activities. Specifically, the study sought to examine:

i. The function of Teachers' IC in teaching netball shooting skill to pre-service teachers.

ii. The extent of supervision of netball activities among pre-service teachers.

iii. The frequency of pre-service teachers participated in netball activities.

iv. Pre-service teachers' knowledge of the rules and basic skills in netball.

v. The extent to which pre-service teachers could identify basic skills in netball.

\section{Methods}

\subsection{Study Design}

We used descriptive design to provide insight into netball activities relating to teachers' utilization of instructional cues in teaching shooting skill, supervision of netball activities among pre-service teachers, frequency of participation, and knowledge level of pre-service teachers in the fundamental skills of netball. Through the use of descriptive techniques, we video-taped students and teachers in a practical teaching and learning situation involving shooting skill in netball. These descriptive processes enabled assessment of attitudes, thoughts, opinions, and feelings of participants to be reported meaningfully. Typically, the study involved practical work in which teaching and learning behaiours were video-recorded in natural PE setting.

\subsection{Participants}

A total of 81 subjects (students $=77$, teachers $=4$ ) were involved in the study. Specifically, 31 respondents (male $=12$, female $=19)$ were sampled from St. Francis' College. Subjects sampled from St. Theresa's College were 31 (female=31). St. Theresa's College was a female institution. From E.P. College, 15 subjects (male=12, female=3) were drawn. In all, 28 male participants $(35 \%)$ were used, while 53 female participants $(65 \%)$ were also part of the study. In addition, four PE teachers were sampled for the study. They were all male teachers because there was no female teacher in the three institutions where the study was conducted. Of these four PE teachers, two were involved in a practical teaching that lasted 60 minutes and the other two were involved in teaching schedules that determined the effectiveness of teachers' IC in a shooting task (the effectiveness of teachers' IC on a shooting skill is presented separately in another report).

\subsection{Data Collection}

The main data collection instrument was event recording tool which was self-developed from observational data collection system. This instrument was validated by an experienced University researcher in the area of PE. Event recording instrument is useful for collecting data on welldefined behaviours that can be measured by counting the number of times the event happens. Event recording instrument can be used to measure several aspects of teachers and learners in an instructional setting. Frequency count of events can be converted to rate per minute. In general, the data collection procedures for this study involved:

i. There were two training sessions for research assistants, recorders and the selected PE teachers involved in the study.

ii. All student participants were drawn from homogeneous group who were at the beginning phase of learning the fundamentals of netball game.

iii. The study participants were put into three main groups for data collection on three sets of students-teacher behaviours. GROUP A comprised of PE teachers $(n=4)$ whose mandate was to use IC in teaching shooting skill in pedagogical setting. GROUP B comprised of student participants (pre-service teachers, $n=32$ ) used in the 60 minutes lesson period (two classes of 16 subjects; each class lasted 30 minutes). GROUP C encompassed student participants (pre-service teachers, $n=45$ ) used in the two schedules of shooting task to determine the effects of IC on shooting (i.e., teaching schedules with IC and without IC). It should be noted that GROUP B and $\mathrm{C}$ were homogeneous groups of pre-service teachers.

iv. As part of demographic information gathering, we requested subjects to respond to issues relating to supervision of netball activities, the frequency of 
participation in netball activities, knowledge in the rules and basic skills of netball.

v. There was objective analysis of data, establishing interobserver reliability between two independent recorders. Means, percentages, and rate per minute of various data were generated from the inter-observer evaluation of the two independent recorders.

\subsection{Analyses}

Data from the video-recorded lesson was evaluated using inter-observer evaluation procedures. Inter-observer reliability checks between the two independent recorders were carried out to ensure reliability of data. The interObserver Agreement (IOA) was calculated as:

\section{Agreement \\ $\overline{\text { Agreement + Disagreement }}$ \\ $\mathrm{X} 100=\%$ of agreement}

In this context, agreement means the degree to which independent observers agree on what they see and record (Donkor, Nyavor, Addai-Tuffour, et al. 2021 [7]; Donkor, Nyavor, Atsu, et al., 2021) ${ }^{[7]}$. Ideally, IOA of at least $80 \%$ should be considered a good reliability. This requirement is in line with the statement that: "A reliability of 80 percent is usually considered necessary for research purposes" (Siedentop, \& Tannehill, 2000, p.338) ${ }^{[17]}$. As indicated by Siedentop and Tannehill, the event recording instrument is "one of the most useful methods of collecting meaningful data; any action or reaction of a student or teacher and any aspect of interaction between student and teacher that can be defined can be measured by counting the number of times it occurs" (p. 325).

\section{Results}

\subsection{Demographics}

Analysis based on the total number of subjects $(n=81)$ revealed that 31 pre-service teachers (males $=12$, females=19) were drawn from St. Francis' College. Preservice teachers drawn from St. Theresa College were also 31. All subjects from St. Theresa's College of Education were females because this study site was a female institution. In addition, 15 subjects (males $=12$, females $=3$ ) were drawn from E.P. College. All the 4 PE teachers sampled for the study were males (there was no female PE teacher in the four institutions used for the study). Table 1 specifies the composition of the subjects.

Table 1: Composition of Subjects $(n=81)$

\begin{tabular}{|c|c|c|c|c|c|c|}
\hline \multirow{2}{*}{ College/Group } & \multicolumn{2}{|c|}{ Male } & \multicolumn{2}{c|}{ Female } & \multicolumn{2}{c|}{ Total } \\
\cline { 2 - 7 } & F & $\mathbf{\%}$ & $\mathbf{f}$ & $\mathbf{\%}$ & F & \% \\
\hline St. Francis College & 12 & 15 & 19 & 23 & 31 & 38 \\
\hline St. Theresa College & - & - & 31 & 38 & 31 & 38 \\
\hline E.P. College & 12 & 15 & 3 & 4 & 15 & 19 \\
\hline PE Teachers & 4 & 5 & - & - & 4 & 5 \\
\hline TOTAL & 28 & 35 & 53 & 65 & 81 & 100 \\
\hline
\end{tabular}

Subjects were put into three main groups. GROUP A indicates the number of PE teachers $(n=4)$ whose mandate was to deliver Instructional Cues (IC) in an instructional setting. GROUP B indicates the number of pre-service teachers $(n=32)$ used in the 30 minutes lesson for each of the two classes observed. GROUP $\mathrm{C}$ indicates the number of student participants (pre-service teachers, $n=45$ ) used in the two schedules of shooting task to determine the effects of IC on shooting (i.e., with IC/without IC). GROUP B and C were homogeneous groups of pre-service teachers that were used in different schedules to collect two sets of data; one on the use of IC and the other on the determination of the effects of IC on shooting skill. In all, 38 male participants representing $35 \%$ were used, while 53 female participants representing $65 \%$ were also used in the study. Table 2 presents groups of subjects used for the study.

Table 2: Subjects for the Study

\begin{tabular}{|c|c|c|c|c|c|}
\hline Gender & $\begin{array}{c}\text { Group } \\
\text { A }\end{array}$ & $\begin{array}{c}\text { Group } \\
\text { B }\end{array}$ & $\begin{array}{c}\text { Group } \\
\text { C }\end{array}$ & Total & $\begin{array}{c}\text { Percent. } \\
(\boldsymbol{\%})\end{array}$ \\
\hline Male & 4 & 2 & 22 & 28 & 35 \\
\hline Female & 0 & 30 & 23 & 53 & 65 \\
\hline Total & 4 & 32 & 45 & 81 & 100 \\
\hline
\end{tabular}

\begin{tabular}{|c|c|}
\hline \multicolumn{2}{|c|}{ Groups Of Study Participants } \\
\hline A : & $\begin{array}{c}\text { Indicates the number of PE teachers whose mandate } \\
\text { was to use IC in teaching shooting skill to pre-service } \\
\text { teachers. }\end{array}$ \\
\hline $\begin{array}{c}\text { Group } \\
\text { B: }\end{array}$ & $\begin{array}{c}\text { Indicates the number of pre-service teachers used in } \\
\text { the } 30 \text { minutes lesson for each of the two observed } \\
\text { classes. }\end{array}$ \\
\hline $\begin{array}{c}\text { Group } \\
\text { C: }\end{array}$ & $\begin{array}{c}\text { Indicates the number of pre-service teachers used in } \\
\text { the two schedules of teaching (with IC and without IC) } \\
\text { a shooting task to determine the effects of IC on } \\
\text { shooting. }\end{array}$ \\
\hline
\end{tabular}

\subsection{Supervision of Netball Activities among Pre-Service} Teachers

According to the data, five respondents $(6 \%)$ were of the view that supervision during netball activities was very high, 16 respondents $(21 \%)$ said supervision was high while 36 respondents $(47 \%)$ held the opinion that supervision was moderately carried out by their PE teachers in the Colleges. Respectively, 5 respondents $(6 \%), 6$ respondents $(8 \%)$ and 9 respondents $(12 \%)$ indicated that supervision of netball activities in their colleges was low, very low or needs improvement. Table 3 presents the results on supervision of pre-service teachers in netball activities.

Table 3: Supervision of Pre-Service Teachers in Netball Activities

\begin{tabular}{|c|c|c|}
\hline Category & Frequency (f) & Percent. (\%) \\
\hline Very High & 5 & 6 \\
\hline High & 16 & 21 \\
\hline Moderate & 36 & 47 \\
\hline Low & 5 & 6 \\
\hline Very Low & 6 & 8 \\
\hline Needs Improvement & 9 & 12 \\
\hline Total & 77 & 100 \\
\hline
\end{tabular}

\subsection{Frequency of Participation in Netball Activities among Pre-Service Teachers}

Analysis of responses shows that the frequency at which students participated in netball activities was rated $0 \%$ in the high and very high categories, 4\% (3 respondents) for moderate category. Respectively, respondents recorded $60 \%$ (46 respondents), 29\% (22 respondents) and 8\% (6 respondents) for low, very low and needs improvement categories. Table 4 presents data on pre-service teachers' participation in netball activities. 
Table 4: Frequency of Pre-service Teachers' Participation in Netball Activities

\begin{tabular}{|c|c|c|}
\hline Category & Frequency (f) & Percentage (\%) \\
\hline Very High & 0 & 0 \\
\hline High & 0 & 0 \\
\hline Moderate & 3 & 4 \\
\hline Low & 46 & 60 \\
\hline Very Low & 22 & 29 \\
\hline Needs Improvement & 6 & 8 \\
\hline Total & 77 & 100 \\
\hline
\end{tabular}

\subsection{Knowledge of the rules of netball}

Analysis of data suggests that 77 subjects self-rated their knowledge level of the rules pertaining to netball. The rating in the categories of very high and high recorded $0 \%$ for all respondents $(n=0)$. Only 3 students $(4 \%)$ were of the view that they had moderate level of knowledge in the rules of netball, while 12 respondents $(16 \%)$ revealed that they had very low knowledge in the rules of netball. As many as 42 respondents $(54 \%)$ were of the view that their knowledge of the rules pertaining to netball needed improvement. Table 5 presents pre-service teachers' knowledge of the rules of netball.

Table 5: Pre-Service Teachers' Knowledge Level in Netball Rules

\begin{tabular}{|c|c|c|}
\hline Category & Frequency (f) & Percentage (\%) \\
\hline Very High & 0 & 0 \\
\hline High & 0 & 0 \\
\hline Moderate & 3 & 4 \\
\hline Low & 20 & 26 \\
\hline Very Low & 12 & 16 \\
\hline Needs Improvement & 42 & 54 \\
\hline Total & 77 & 100 \\
\hline
\end{tabular}

\subsection{Knowledge of the Basic Skills in netball}

Subjects were asked to list the skills in netball. Analysis of data revealed that 77 subjects produced 151 responses pertaining to the skills in netball. It was observed that $73 \%$ (56 respondents), were able to identify shooting as a skill in netball, catching skill recorded $55 \%$ (42 respondents). Throwing skill recorded $40 \%$ (31 respondents), while pivoting could not be mentioned as a basic skill in netball by any of the respondents. Passing skill was identified by $29 \%$ (22 respondents) of the subjects as a skill in netball. No other skill in netball could be mentioned by any of the respondents. Table 6 presents the results on pre-service teachers' ability to identify basic skills in netball.

Table 6: Pre-Service Teachers' Identification of Basic Skills in Netball

\begin{tabular}{|c|c|c|c|}
\hline Category & $\begin{array}{c}\text { № of respondents } \\
\text { (f) }\end{array}$ & $\begin{array}{c}\text { oo of responses } \\
\text { (n) }\end{array}$ & $\begin{array}{c}\text { Percentage } \\
(\%)\end{array}$ \\
\hline Shooting & 77 & 56 & 73 \\
\hline Catching & 77 & 42 & 55 \\
\hline Throwing & 77 & 31 & 40 \\
\hline Pivoting & 77 & 0 & 0 \\
\hline Passing & 77 & 22 & 29 \\
\hline Other skills & 77 & 0 & 0 \\
\hline Total & 462 & 151 & 33 \\
\hline
\end{tabular}

3.6 The Use of ICs in Teaching Shooting Skill in Netball

Analysis of inter-observer data suggests that the frequency count of events for constructive verbal IC was 39 for the first observer and 37 for the second observer. The mean observation score for the two observers was 38. Data for this category of verbal IC yielded inter-observer reliability of $95 \%$. Additionally, observer one recorded 41 events while observer two recorded 38 events for constructive non-verbal IC. The mean observation score of 39.5 events was documented with inter-observer reliability of $93 \%$. For destructive verbal IC, both the first and second observers documented 18 events each with a mean score of 18 which achieved $100 \%$ data reliability for this category. Both the first and second observers recorded 8 events for destructive instructional cues that were non-verbal. The two observations produced a mean score of 8 events with data reliability of $100 \%$ for this category. Table 7 presents data on teachers' utilization of IC in teaching shooting skill in netball.

Table 7: Teachers' Utilization of ICs in Teaching Netball Shooting Skill

\begin{tabular}{|c|c|c|c|c|c|c|}
\hline \multirow{2}{*}{ Function } & Type & \multirow{2}{*}{ Observer1 } & \multirow{2}{*}{ Observer2 } & \multirow{2}{*}{ Inter-Observer Mean Score } & \multicolumn{2}{|c|}{ Inter-Observer Reliability of Data } \\
\hline \multirow{3}{*}{ Constructive } & Verbal & 39 & 37 & 38 & $\frac{37}{37+2} \times 100$ & 95 \\
\cline { 2 - 7 } & Non-verbal & 41 & 38 & 39.5 & $\frac{38}{38+3} \times 100$ & 93 \\
\hline \multirow{3}{*}{ Destructive } & Verbal & 18 & 18 & 18 & $\frac{18}{18+0} \times 100$ & 100 \\
\cline { 2 - 7 } & Non-verbal & 8 & 8 & 8 & $\frac{8}{8+0} \times 100$ & 100 \\
\hline \multicolumn{2}{|c|}{ Total } & 106 & 101 & 03.5 & $\frac{101}{101+5} \times 100$ & 95 \\
\hline
\end{tabular}

\subsection{Rate per Minute of Teachers' Utilization of IC}

Each category of constructive and destructive instructional cue was calculated in rate per minute. The table shows interobserver frequency of events as 38,39.5, 18 and 8 for constructive verbal IC, constructive non-verbal IC, destructive verbal IC and destructive non-verbal IC respectively. A total of 103.5 inter-observer score was recorded for the entire one-hour observation of the practical lesson. The rate per minute of the use of teachers' IC was $0.6,0.7,0.3,0.1$ and 0.7 for constructive verbal IC, constructive non-verbal IC, destructive verbal IC and destructive non-verbal IC respectively. On average, 1.7 instructional cues were used each minute during the practical lesson that lasted 60 minutes. Table 8 presents rate per minute of teacher's IC. 
Table 8: Rate per Minute of Teachers' Utilization of ICs [Length of Observation $=1 \mathrm{hr}$ (60 minutes)

\begin{tabular}{|c|c|c|c|c|}
\hline Use & Type of IC & Inter-Observer Frequency & Equation & Rate Per Minute \\
\hline \multirow{3}{*}{ Constructive } & Verbal IC & 38 & $\frac{38}{60}$ & 0.6 \\
\cline { 2 - 5 } & Non-verbal IC & 39.5 & $\frac{39.5}{60}$ & 0.7 \\
\hline \multirow{2}{*}{ Destructive } & Verbal IC & 18 & $\frac{18}{60}$ & 0.3 \\
\cline { 2 - 5 } & Non-verbal IC & 8 & $\frac{8}{60}$ & 0.1 \\
\hline \multicolumn{2}{|c|}{ Total } & 103.5 & $\frac{\mathbf{1 0 3}}{\mathbf{6 0}}$ & $\mathbf{1 . 7}$ \\
\hline
\end{tabular}

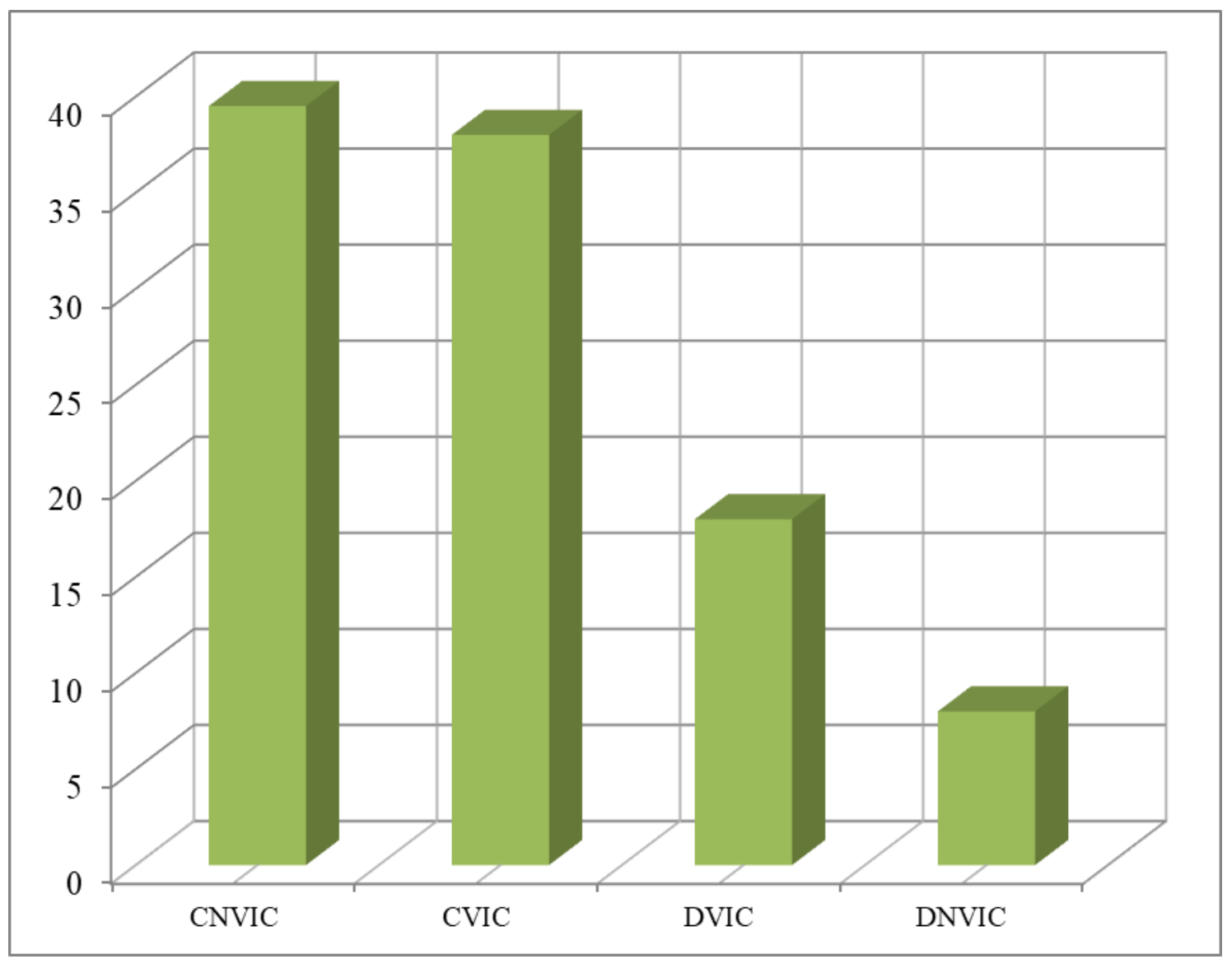
Keys
CNVIC - Constructive non-verbal instructional cues (39.5 events)
CVIC - Constructive verbal instructional cues (38 events)
DVIC - Destructive verbal instructional cues (18 events)
DNVIC - Destructive non-verbal instructional cues ( 8 events)

Fig 1: Order of magnitude by which teachers' ICs were used

\section{Discussion}

The relevance of instructional cues in teaching and learning environment has been previously reported (i.e., Alpizar, et

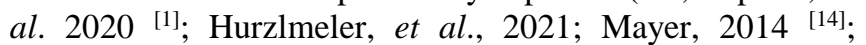
Raisbeck \& Yamada, 2019 [15]; Richter, et al. $2016^{\text {[16]; }}$ Schneider et al., 2018). Findings of this study suggested that teachers were able to control destructions in the utilization of instructional cues in teaching a practical skill in physical education setting. In an instructional setting, students should be given information that is specific and relevant to the critical skill point. It is important to note that relevant information in pedagogical setting captures attention and thus "promotes learning and problem solving" (Klein et al., 2019) ${ }^{[13]}$. The ability of the teacher to control destructions in pedagogical setting is paramount to the learning of proper techniques of the skill.
According to the findings, constructive ICs regularly occurred more than destructive ICs in the entire lesson period. It is ideal for teachers to administer instructions that identify and emphasize positive elements of the task in a manner that helps students to retain and maintain the technique of the skill being taught. One of the meaningful ways of influencing learning outcomes is for teachers to provide corrective suggestions on students' tasks (Hattie \& Timperley, 2007) [11]. The findings also reveal teachers' ability to minimize and control the use of destructive IC which manifested in inter-observer score of only 26 events out of a total inter-observer score of 103.5 events. It was also found that PE teachers provided more verbal IC to the group than to the individual students. Again, non-verbal ICs which were mostly gestures and demonstrations were provided to specific individual students more than the entire 
general group or class. Cues do not add new information to the skill being taught or change the instructional material (De Koning, et al., 2009) ${ }^{[4]}$. However, cueing aids learners 'cognitive process by helping the learner to acquire relevant information relating to the material being learnt.

Each minute, students received IC relating to the proper techniques of performing assigned task. For students to receive a teacher's IC each minute implies that students were actively and regularly monitored and offered assistance to enable them perform the skill correctly. It was also found that constructive non-verbal ICs frequently occurred throughout the lesson period.

On instructional supervision, respondents reported that PE teachers were committed to a good system of monitoring to help them participate in netball activities. Specifically, most the pre-service teachers responded that supervision of students in the Colleges of education was very high. It is indicated that, "supervision has a function to direct, coordinate, develop, guide and organize others in achieving the objectives which are set out in the school situation leading to the sense that supervision has a significant meaning to give help and guidance" (Sudarjat, et al., 2015) [18]. Sudarjat et al. explain further that "The process of supervision is part of the school superintendent's task in implementing the views or approaches that involve teachers to optimally apply their whole creativities" and that "Supervision is often translated as keeping an eye on, ... to help and to participate in efforts to improve the quality, ... and learning situations" (p.148). In this study, monitoring and supervision of netball activities among study participants could be described as good enough. With this scenario, it is ideal for teachers to build their daily monitoring strategies around supporting students to enable them achieve maximum instructional goal (DiPola \& Wagner, 2018, Donkor, 2021) ${ }^{[5,6]}$.

Results suggested that students did not regularly engage in netball activities and that there was generally low participation of both men and women in physical activities involving netball. This situation could be due to the marginalization of the netball game and the fact that many male students see the game as women sport. It should be noted that although the game is generally women dominated, all student teachers in all colleges of education in Ghana are expected to participate, learn and teach fundamental skills of the game in the basic schools of Ghana. In addition, there was deficiency in students' ability to identify the basic skills involved in netball. Most subjects admitted that their knowledge in netball rules needed improvement. Apart from shooting and catching, less than half of the students could mention other basic skills of netball. Again, this could be due to lack of interest and marginalization of the netball game and for the fact that the game was not as popular as other games like football, volleyball, handball etc. in Ghana. This also implies that not many student teachers could be effective teachers of the skills of netball in an instructional setting. In the study, most students could not identify or mention pivoting as a basic skill in netball. This situation should be worrying especially when all pre-service teachers are required to implement the PE programme including aspects of netball in the basic school settings. This situation is a potential threat to the effective teaching of netball in the basic schools. Notwithstanding the challenges revealed so far, netball activities are increasingly becoming popular in most countries.

\section{Conclusions}

Based on the findings of the study, the following conclusions were reached:

1. Physical education teachers were committed to a good system of supervising students in netball activities.

2. Most Pre-service teachers in the colleges where the study was conducted were deficient in the ability to identify basic skills in netball. These pre-service teachers did not regularly engage in netball activities.

3. The PE teachers involved in the study were able to control destructions in the use of instructional cues in teaching a practical skill in physical education setting. These professional PE teachers provided more verbal ICs to the general group as a whole than to the specific individual students in the practical PE lesson involving shooting task in netball.

4. During practical lessons, participants regularly receive IC relating to the proper technique of the skill being taught.

\section{Recommendation}

The correct skill of shooting in netball should be individualized and that coaches and physical educators should provide critical information of skill points to help low-knowledge students acquire relevant techniques of the movement skill being taught. Monitoring mechanisms and practical schedules for netball activities should be given more attention in schools and higher institutions of learning. In this regard, more research in the area of netball should be conducted to raise awareness that will increase male and female participation in the game.

\section{Contribution of Authors}

1. Samuel Kofi Donkor, $\mathrm{PhD}$ - Conception and design of the study

2. The rest of the authors contributed to various phases of the study involving literature review, data interpretation and presentation, results write-ups and discussion of findings.

\section{Conflict of Interest Statement}

With respect to this study, we declare that there is no potential conflict of interest in the publication of this article.

\section{References}

1. Alpizar D, Adesope OO, Wong RM. A meta-analysis of signaling principle in multimedia learning environments. Educational Technology Research and Development. 2020;68(5):2095-2119.

2. Becker KA, Fairbrother JT. The use of multiple externally directed attentional focus cues facilitates motor learning. International Journal of Sports Science \& Coaching. 2019;14(5):651-657.

3. Bruce L, Brooks ER, Woods CT. Team and seasonal performance indicator evolution in the ANZ Championship netball league. Journal of sports sciences. 2018;36(24):2771-2777.

4. De Koning BB, Tabbers HK, Rikers RM, Paas F. Towards a framework for attention cueing in instructional animations: Guidelines for research and 
design. Educational Psychology Review. 2009;21(2):113-140.

5. DiPaola M, Wagner CA. Improving instruction through supervision, evaluation, and professional development. IAP. 2018.

6. Donkor SK. Adequacy of pre-service teacher education for teaching physical education curriculum in public primary schools: A study of teachers from six selected educational circuits. International Journal of Physiology, Nutrition and Physical Education. 2021;6(2):259-264.

7. Donkor SK, Nyavor LG, Addai-Tuffour P, Abieraba RSK, Sorkpor RS, Ocansey R. Intra-observer evaluation of teacher-student questioning behaviours: A case study of the quality and frequency of questions administered in physical education theory class. International Journal of Physical Education, Sports and Health. 2021;8(5):192-197.

8. Donkor SK, Nyavor LG, Atsu FS, Appiah M, Darko RA, Abieraba RSK et al. Evaluation of student-teacher questions: A study of pedagogical practices relating to proportions and rate per-minute of questions asked in physical education class setting. International Journal of Physiology, Nutrition and Physical education. 2021;6(2):265-271.

9. Fennell C, Peroutky K, Glickman EL. Effects of supervised training compared to unsupervised training on physical activity, muscular endurance, and cardiovascular parameters. MOJ Orthopedics \& Rheumatology. 2016;5:00184.

10. Gokeler A, Benjaminse A, Welling W, Alferink M, Eppinga P, Otten B. The effects of attentional focus on jump performance and knee joint kinematics in patients after ACL reconstruction. Physical therapy in sport. 2015;16(2):114-120.

11. Hattie J, Timperley H. The power of feedback. Review of educational research. 2007;77(1):81-112.

12. Hurzlmeier M, Watzka B, Hoyer C, Girwidz R, Ertl B. Visual Cues in a Video-Based Learning Environment: The Role of Prior Knowledge and its Effects on Eye Movement Measures. In Proceedings of the 15th International Conference of the Learning SciencesICLS 2021. International Society of the Learning Sciences. 2021.

13. Klein P, Viir J, Kuhn J. Visual cues improve students' understanding of divergence and curl: Evidence from eye movements during reading and problem solving. Physical Review Physics Education Research. 2019;15(1):010126.

14. Mayer RE. Incorporating motivation into multimedia learning. Learning and instruction. 2014;29:171-173.

15. Raisbeck LD, Yamada M. The effects of instructional cues on performance and mechanics during a gross motor movement. Human movement science. 2019;66:149-156.

16. Richter J, Scheiter K, Eitel A. Signaling text-picture relations in multimedia learning: A comprehensive meta-analysis. Educational Research Review. 2016;17:19-36.

17. Siedentop D, Tannehill D. Traditional Methods For Assessing Teaching. Developing Teaching Skills in Physical Education. 2000, 324-328.

18. Sudarjat J, Abdullah T, Sunaryo W. Supervision, leadership, and working motivation to teachers' performance. International Journal of Managerial Studies and Research (IJMSR). 2015;3(6):146-152. 